\title{
Three Strategies for Sustainable Design in the Developing World Anthony Crabbe
}

\section{Introduction}

The difference between contemporary and past views of "sustainability" is that the term currently references an immense project, first internationalized in the early 1980s through the United Nations leadership of a World Commission on Environment and Development. The commission's 1987 Brundtland Report, Our Common Future, applied the notion of sustainability to all of the following: the international economy, global population, food security, species and ecosystems, energy, industry, urbanism, oceans and space, and peace and security. ${ }^{1}$ Note that this understanding of sustainability subsumes even those notions of natural and human "ecology" that designers like Victor Papanek started to urge their colleagues to address in the early 1970s. Also interesting is that the term "sustainability," is never used in Papanek's Design for the Real World, ${ }^{2}$ and it is mentioned only eight times en passant in William McDonough's 2002 environmental design tract, From Cradle to Cradle. ${ }^{3}$ The larger scope of the UN definition then makes it hard to think of "sustainable" design as anything other than one component of a holistic plan for global survival that involves a host of specialized disciplines beyond design.

Viewed in this context, it is hard to identify a short list of criteria for sustainable practices in any discipline, particularly in a "cross-disciplinary" one such as design. Nevertheless, this paper takes a modest first step by reviewing a small subset of sustainable design-and-make projects that are part of the global project of sustainability, in order to identify and comprehend their strategies, and where possible, to evaluate the efficacy of these strategies from the grand perspective of sustainable development. The only set of overarching sustainability metrics I consider in this review is the "Natural Step," proposed by K-H Robèrt et al.," which comprises four measures they acknowledge as open to refinement and not directly applicable to every issue raised in the Brundtland Report. ${ }^{5}$ Otherwise, this review is not consciously predicated upon theoretical notions of either design or sustainability. I have selected three case studies as vehicles for what might be termed a phenomenological investigation of differing approaches to "sustainable" design practice. 
6 David Brown, "Richest tenth own $85 \%$ of world's assets," Sunday Times, December 6, 2006.

7 World Bank, 2008, http://web.worldbank. org/wbsite/external/topics/extpoverty/0 "contentMDK:21517391 menuPK:33699 8 pagePK:64020865 piPK:149114 -theSi tePK:336992,00.html (accessed February 11, 2011).

8 World Bank, NGO Research Guide, 2006, http://ibrary.duke.edu/research/subject/ guides/ngo_guide/igo_ngo_coop/ngo_ wb.html (accessed February 10, 2011).

9 R. L. Stirrat and Heiko Henkel, "The Development Gift: The Problem of Reciprocity in the NGO World," Annals of the American Academy of Political and Social Science 554 (1997), 66-80.

10 IndianNGOs.com, http://www.westgodavari.org/NGO/WHATISNGO.asp (accessed February 11, 2011).
Beyond the 1980 s, at a time when $2 \%$ of the world's population now owns $50 \%$ of its wealth, ${ }^{6}$ and half of the world's individuals live on less than US\$2 a day, there are tens of thousands of organizations in the developed world charitably offering their design and development expertise to help neighbors in the developing world create products and systems for providing basic needs such as water, fuel and housing. In this context, the term "sustainable" applies not only to responsible and effective management of resources, but also to the preservation of life. Non-governmental organizations (NGOs), charities, and social businesses currently follow a number of sustainable design strategies, including the following three:

1. Charitable strategies: Using developed world know-how to design products and systems that can be charitably distributed in developing world communities.

2. Networked strategies: Enabling developing world communities to work collaboratively with international networks in designing and developing their own products and systems for both personal use and communal income generation.

3. Social business strategies: Harnessing artisanal designand-make skills to create self-sustaining social businesses in developing world communities that can sell their products in both local and export markets.

Strategy 1 is the simplest and quickest way to deliver products and systems to countries without the manufacturing or market infrastructure to introduce, for example, medicines, machinery, or telecommunications and IT products and services-items that could not be introduced as a result of following either strategy 2 or strategy 3. However, unlike strategies 2 and 3 , strategy 1 is sustainable only as long as developed world communities remain supportive of charitable causes. Both donors and recipients alike are concerned that strategy 1 runs the risk of sustaining a culture of both financial and political dependency in developing world communities. ${ }^{9}$ Strategies 2 and 3 may then be seen as endeavors to improve the capacity of recipients to manage their basic needs independently, and even profitably. In this regard, they score better under most current sustainability metrics-for example, under the "fourth principle" of the Natural Step, a set of principles, each derived from four proposed "system conditions" of nature, shown in Table 1.

Infrastructure and investment are the most important factors determining which of strategies 1, 2, or 3 is the most appropriate to local need. For example, in India alone, there are between 1.5 and 3 million NGOs operating mostly on life-sustaining projects. ${ }^{10}$ However, the booming Indian economy is now a major exporter of the machinery used for water, sanitation, fuel, and building 
Table 1 | Natural Step System Conditions and Principles of Sustainability

\begin{tabular}{l|l}
$\begin{array}{l}\text { The Four System Conditions } \\
\text { In a sustainable society, nature is not subjected to } \\
\text { systematically increasing: }\end{array}$ & $\begin{array}{l}\text { Reworded as The Four Principles of Sustainability } \\
\text { To become a sustainable society we must: }\end{array}$ \\
\hline $\begin{array}{l}\text { 1. concentrations of substances extracted from the } \\
\text { earth's crust }\end{array}$ & $\begin{array}{l}\text { 1. eliminate our contribution to the progressive buildup of substances extracted } \\
\text { from the Earth's crust (for example, heavy metals and fossil fuels) }\end{array}$ \\
\hline 2. concentrations of substances produced by society & $\begin{array}{l}\text { 2. eliminate our contribution to the progressive buildup of chemicals and } \\
\text { compounds produced by society (for example, dioxins, PCBs, and DDT) }\end{array}$ \\
\hline $\begin{array}{l}\text { 3. degradation by physical means } \\
\begin{array}{l}\text { 4. and, in that society, people are not subject to } \\
\text { conditions that systemically undermine their } \\
\text { capacity to meet their needs }\end{array}\end{array}$ & $\begin{array}{l}\text { 4. eliminate our contribution to conditions that undermine people's capacity to the progressive physical degradation and } \\
\text { meet their basic human needs (for example, unsafe working conditions and } \\
\text { not enough pay to live on). }\end{array}$
\end{tabular}

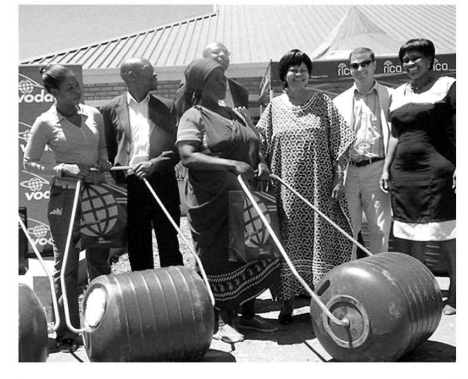

Figure 1

Hippo Water Roller.

(c) Hippo Water Roller Project, Fourways, 2055, South Africa (This image is the product of a previous relationship with Hippo Water International, with which the Hippo Water Roller Project is no longer associated).

11 Wikipedia, http://en.wikipedia.org/wiki/ List_of_countries_by_GDP_(nominal) (accessed February 12, 2011).

12 Volker Beckmann and Martina Padmanabhan, "Observability, Measurability, and Data Availability" in Institutions and Sustainability: Political Economy of Agriculture and the Environment - Essays in Honour of Konrad Hagedorn, Beckmann and Padmanabhan, eds.. (Berlin: Springer, 2009), 353-57.

13 Janine Erasmus, "Tapping into Ingenuity," MediaClubSouthAfrica. com, July 1, 2008, http://www. mediaclubsouthafrica.com/index. php?option=com_content\&view= article \&id $=549 \% 3$ Atapping-intoingenuity010708\&catid $=42 \% 3$ Aland news\&ltemid=51 (accessed May 15, 2011). industries in the developing world. By contrast, troubled states like Southern Sudan or Timor-Leste have scarcely any industrial infrastructure, or a collapsed one. As the world's tenth largest economy, ${ }_{11}^{11}$ India is then far better placed than many other nations to independently address sustainability problems, and the kind of assistance that communities there may require is likely to be very different from that required in less technologically developed and politically stable nations. Designers, then, must be aware of both the political and economic context of the area for which they are designing-factors that are not perhaps as clear in principle 4 of the Natural Step metrics as in other metrics or agency views..$^{12}$ The following sections examine the detail of each of the three identified design strategies (i.e., charitable, networked, and social business) by reference to case studies featuring, respectively, Imvubu Projects, the Legacy Foundation, and Traidcraft.

\section{Case Study 1: Charitable Design}

The Hippo Roller is a water collecting device designed and manufactured in South Africa in 1992 and manufactured and distributed since 1998 by a local social enterprise, Imvubu Projects. ${ }^{13}$ As indicated in Figure 1, the design solution is to adapt a 90-liter water barrel into a roller that can be pushed to a distant water supply, such as a stream, into which it may be immersed and filled. The barrel cap is then screwed back on and the barrel is pushed or hauled home using the rigid hooped handle fixed to the barrel axis-an operation that requires far less mechanical work than carrying filled water containers, and enables the carrier to transport five times the volume of water on each trip. Around 30,000 of these cleverly designed products have been distributed to date, including exports to other sub-Saharan African nations lacking the technology base found in South Africa, which would enable them to rotationally mold their own rollers. Since the manufacturing cost of the Hippo is around $\$ 80$, it is unaffordable even to most users in South 
Africa, and so its distribution is almost entirely dependent upon foreign gift aid and sponsorship, organized principally through the Africa Foundation and UNICEF. The efforts of these two organizations have recently been supported by an American-based NGO, Hippo Water International, which has helped sponsor a redesign carried out by a San Francisco sustainable design consultancy, Project $\mathrm{H}$. The new design splits the original unitary rotomolded barrel into two parts to allow nested stacking during transport."

On the face of it, then, the Hippo is an outstandingly successful, locally developed product-a simple, robust solution that helps desperately poor people meet an essential survival requirement. However, any fuller measure of its sustainability would reveal difficulties, of which Imvubu appears well aware: First, it is a product that can be neither manufactured nor afforded by its users, who are accordingly made dependent on charity coming from other countries and organizations, which do not have a neutral view about the exchange rates for gift aid, as Stirrat and Henkel point out. ${ }^{15}$ Second, if Hippo is distributed in areas where local water supplies can sustain only limited populations, its greatly increased efficiency may contribute to the over-exploitation of those supplies. Water management is a global issue not sufficiently transparent in the third principle of the Natural Step, because the gradual redistribution of water around the planet is a natural process, irrespective of human contributions. Freshwater depletion is a problem serious enough to threaten the well-being of every nation on earth, evidenced by population migrations and conflicts over the sharing of common water resources, such as those which helped trigger the Six-Day War of 1966 between Israel and its neighbors. ${ }^{16}$ Third, it is not clear what recycling system is in place to manage Hippo Rollers at the end of their lives.

From this case study, designers might take away the following lessons:

1. They must judge whether a design solution like the Hippo is worthwhile, not just on the basis of the short-term need it addresses, but also on whether it is sustainable in the long term. On the first basis alone, few could doubt Hippo is a very worthwhile project. But on the second basis, a design solution that results in long-term dependency on gift aid cannot be the best solution, however pressing the immediate need (as suggested by Principle 4 of the Natural Step system).

2. The designer cannot be too reliant on metrics such as Natural Step if they lack clear measures for complex issues as important as water management.

3. The designer is unlikely to be capable of conducting a prospective assessment of the sustainability of a design proposal without the assistance and collaboration of 


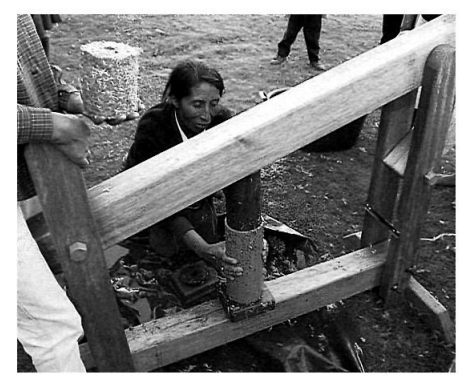

Figure 2

Legacy lever press in use. (C) Legacy Foundation, Ashland, OR 97520, U.S.A. others more expert in the field. This reality emphasizes something already well understood in design circles: The issue of sustainability increasingly demands that design teams be multi-disciplinary, ${ }^{17}$ and that they be capable both of prospectively identifying sustainability issues and of continuing to monitor the environmental impact of their chosen solutions.

\section{Case Study 2: Creating Local Design-and-Make Networks}

The collection of firewood places enormous physical burdens on impoverished women (the principal labor force worldwide), drawing them farther away from their dependents for longer periods. It degrades the principal local source of hunted and gathered food, leads to mass soil erosion and local climate change, and if unchecked over wide areas, threatens the planetary carbon cycle. The U.S.-based Legacy Foundation is dedicated to alleviating this problem by promoting the manufacture and use of fuel briquettes made close to home from local agricultural and urban wastes. Legacy recognizes that the solutions offered by their system are restricted to the preservation of local forestry and the easing of labor demands on wood gatherers. The briquette system does not alleviate the problem of carbon emissions from biofuel combustion.

Unlike Imvubu Projects, Legacy has a philosophy aimed at involving locals in every aspect of their solution-from the design and build to selling surplus briquettes as an additional source of income. The foundation encourages its beneficiaries to take charge of every aspect of the system, using the Internet as its principle means of global communication, not only to disseminate information, but also to recruit volunteers and instructors. The Legacy website, www.legacyfound.org, not only sells modestly priced instruction manuals in pdf form, but also publishes details of local modifications for the appraisal of members across the world. Where these modifications evolve into proven new designs, they are added to the stock of instruction manuals; thus, any innovating user can emerge as a designer and guide within the global user community. In this regard, the Legacy approach may be seen to "score" much better than the Hippo case in terms of Natural Step 4, which is about improving people's ability to support themselves.

However, many of the products showcased in the Legacy literature appear far less cleverly designed than the Hippo Rollerparticularly its main briquette press, which is a lever-type made from wooden planks illustrated in Figure 2. The press design is intended to be one that could be made in any community that has rudimentary carpentry resources, thus allowing for independence from any external agency. The briquette mold tool comprises a wooden plunger that is forced by the lever into a length of plastic waste pipe that has holes drilled in to vent liquids during the pressing process. The design allows sufficient plunger travel to 
18 P. D. Grover and S. K. Mishra, Biomass Briquetting: Technology and Practices, UN FAO GCP/RAS/154/NET Field Document 46 (Bangkok: Regional Wood Development Progamme in Asia, 1996), 5-9.

19 Owen McDougal, Seth Eidemiller, and Nick Weires, "Biomass Briquettes: Turning Waste into Energy," Biomass Magazine, November 23, 2010, http:// biomassmagazine.com/articles/5148/ biomass-briquettes-turning-waste-intoenergy (accessed April 12, 2011).

20 Joel O. Chaney, Michael J. Clifford and Robin Wilson "An Experimental Study of The Combustion Characteristics of Low-Density Biomass Briquettes," Nottingham University report in Engineers without Borders, 2010. www.ewb-uk.org/system/files/ Joel+Chaney+report_0.pdf. (accessed April 12, 2011).

21 Jason Dahlman and Charles Forst, "Technologies Demonstrated at Echo: Briquette Presses for Alternative Fuel Uses," American Society of Farm Managers and Rural Appraisers (2002), http://www.wcasfmra.org/biogas_docs/ Horizonal\%20Biogas\%20Digester. pdf (accessed April 10, 2011) make with each pressing a moist biomass briquette of around $20 \mathrm{x}$ $3.5 \mathrm{~cm}$, with a cured density in the range of $0.2-0.4 \mathrm{~g} / \mathrm{cc}$, depending on the mix of grasses, leaves, woodchip and paper to hand. This is a much lower density than the $1-1.3 \mathrm{~g} / \mathrm{cc}$ achieved by commercial screw or hammering piston machines, which produce briquettes having combustion characteristics similar to wood, ${ }^{18}$ and therefore the thermal efficiency of the hand-pressed briquettes is $25-30 \%$ lower. ${ }^{19,20}$

Commercial machines also extrude briquettes continuously, whereas the lever press is a single-action device requiring the biomass to be packed into the pipe tool by hand and then the briquette pushed out by hand before the pipe can be reloaded. Accordingly, the production capacity of the lever press is less than $10 \%$ that of a small motorized briquette press. ${ }^{21}$ These factors make the highly sustainable Legacy strategy far less attractive than it might be, as I know from personal experience of an on-going project initiated by a local NGO in Timor-Leste. There, the environmental threat is particularly acute because the principal wood fuel is Mangrove root, taken from coastal swamps that are the nurseries for most of the fish caught locally. Barbequing fish and other foods on Mangrove wood fires is endemic to the local culture. Locals believe the wood gives a special flavor to food, and they are expert in judging its burning characteristics. Given the bulky nature of the available agricultural waste and the low compression of the lever presses built for the project, the briquettes needed to contain at least $50 \%$ waste paper to perform as indicated by Legacy literature, which meant the mix was better suited to urban than rural use. So although the locals had no difficulty recognizing the benefits of the Legacy system, its optimal performance required close support from the NGO personnel.

Among the suggestions to consolidate this project in TimorLeste are plans to reformulate it more as a social business, raising capital through a $\$ 2$ subscription and using it to import cast iron No. 12 meat grinders from China, for a cost of around \$15 each for the minimum volume of 200 . These screw grinders are extremely robust and simple to maintain, and they can be either hand-cranked or motor-driven via a belt running on the crank wheel. The grinder mechanism operates exactly like a screw-type briquette machine, producing continuous extrusions that can be broken off from the die. Work in the laboratory shows that the grinder is capable of compressing mixed biomass without sawdust or paper to densities close to $1 \mathrm{~g} / \mathrm{cc}$. The oils expressed from common weeds (e.g., Jatropha gossipifolia) are a far more calorific fuel than mangrove wood, and they can be used as binding agents when the mold is heated and the briquettes torrefied, as is done with commercial machines. 
Such suggestions could then feed back into the Legacy loop of self-sustained design and development; but, the change of design strategy that involves importing and adapting catering machinery requires an initial voluntary capitalization and a business model markedly different from the system developed around the self-build lever press. The lesson here is that even a relatively small modification to part of the product design supported by a Legacy type of network can significantly alter the nature and ethos of that system and can turn an independent community venture into a business one. Thus, the cost of the product becomes subject to market forces, which can make it less affordable to community members and allow those with more capital to profit at the expense of those who have less.

\section{Case Study 3: Design for Fair Trading}

The third case study involves an approach that actually promotes the capitalist business model as a way to alleviate poverty through profitable development of local craft skills. The system is promoted by the U.K. Christian foundation Traidcraft, which started in the 1970s to pioneer what is now well-known as a "Fair Trade" system; it has subsequently spread far beyond craft to include commodity and other forms of production. In terms of its craft products, Traidcraft seeks to enable low-income communities, isolated from the global marketplace but whose members have design-and-make skills, to engage with that market by setting up small private or social businesses. Traidcraft claims its system is sustainable in two ways: First, it creates work cooperatives in low-income communities that are isolated from wealth-creating opportunities. Second, it uses indigenous design-and-make skills not only to make traditional products, but also to transform local waste into secondary products, some having a value as great as the primary one-an approach commonly known today as "upcycling." Examples are bowls made from recycled magazines, and a wash-bag made from discarded tires, illustrated in Figure 3. As Figure 3 also shows, Traidcraft (like Legacy) has harnessed the power of a sophisticated technology - the worldwide web - to publicize and market these technologically unsophisticated products.

Traideraft has gone a step further in presenting its products to a global consumer market through its web store. This strategy naturally places its products alongside those of other stores (e.g., www.myecostore.co.uk), which sell what appear to be nearly identical types of product. However, a key difference between the Traidcraft web store and say, My Eco Store, is that Traideraft are able to exploit the narrative potential of a website to clarify exactly which overseas enterprise is designing and making each product, and how any profit from the purchase benefits that enterprise and the community it supports. The Traidcraft web store is also 
Figure 3

Traidcraft webstore page for recycled tire

(tyre) washbag.

(c) Traidcraft, Gateshead.

\section{Men's Recycled Tyre Washbag}

Code: 67920

Country of Origin: India

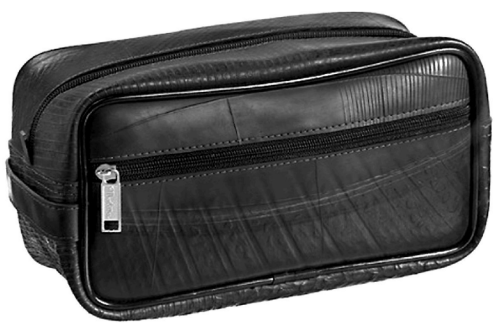

Fair Trade Producer Details: Bhopal

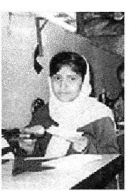

Bhopal Rehabilitation Centre was established in

1985 following the Bhopal gas disaster, with the aim

of assisting in the rehabilitation of victims. Many local

people are still suffering from the long-term after-

effects. Traidcraft Exchange funded a number of

training programmes at $\mathrm{BRC}$, and introduced the

organisation to Traidcraft plc in 2002.

clearly linked to the foundation's site, which gives more information about its aims, its constitution, its trustees, collaborators, and so forth. None of this information is available on the My Eco Store site. Thus visitors might presume its products are still made in similar communities, but be left wondering where the designs originate and whether the craftspeople are, in fact, working under the direction of others more closely connected to the retailer-in other words, wondering whether the craftspeople work just like other outsourced laborers contracted by transnational companies to work in worse conditions and for less pay than would be acceptable in the contractor's home nation.

Although the "ethical" credentials of Traidcraft appear impeccable compared to many of its competitors in this field, it is worth observing that the sustainability pitch used for its up-cycled products is scarcely different. Of course, upcycling is not an activity restricted to developing world artisans; the approach is prevalent among designers of every rank in the developed world as well, from Frank Gehry to design students. An interesting feature of such up-cycled goods is the recurrence of certain design types, such as the recycled tire chair and tables illustrated in Figure 4. Because these designs are not trademarked and originate primarily in India, they are presumably designs appropriated by disparate workshop enterprises all over the subcontinent and exported using standard marketing methods that favor the distributors far more than the designers and makers.

This possibility raises questions about the extent to which the manufacture and marketing of this type of up-cycled product helps meet the founding objective of Traidcraft, which is to close the global poverty gap-or as their website heading says, "to fight poverty through trade." The craft production of upcycled consumer goods certainly provides employment, which is 


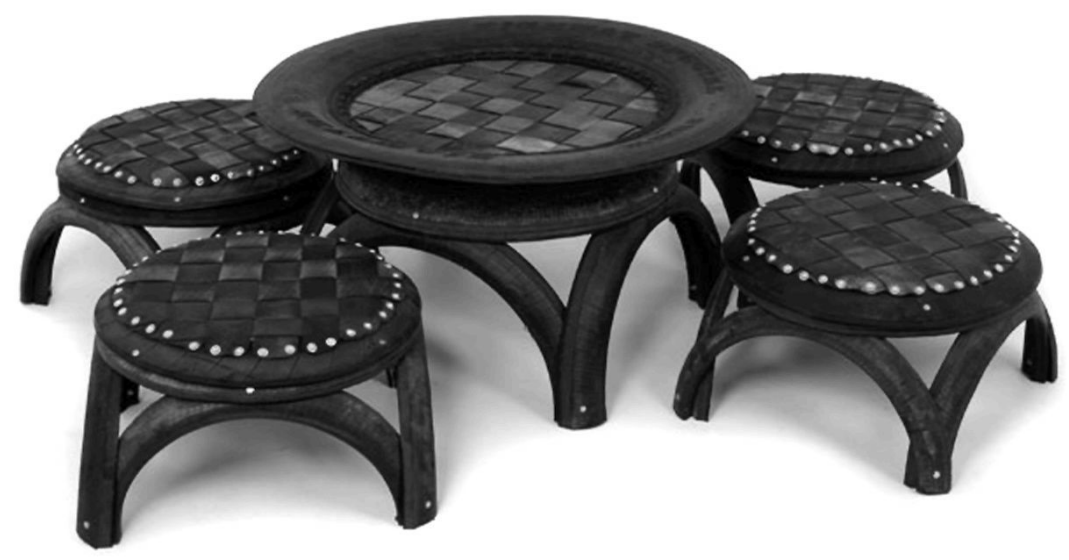

sustainable as long as the demand remains high in local and fickle international consumer markets. However, whether the skills acquired through such work will enable those workers to graduate from being very low-cost artisans to being better paid ones is not easy to predict. Since any poverty "gap" is bound to be relative measure, the concern remains that if a social business relies on making and marketing products that are made affordable by the very low cost of the labor used to manufacture them, then the design-and-make skills being fostered are still very lowvalue ones.

For their part, the companies wearing the "eco badge" to promote products like the tire furniture illustrated in Figure 4 might reasonably claim they are doing their bit to sustain the planet's resources. Because tires have been notoriously difficult to recycle, adapting their remarkable mechanical properties to other uses appears a clever design strategy, which was being promoted by environmental groups and government agencies long before the appearance of the kind of furniture illustrated in developed world marketplaces, as evidenced by the 1995 report of Viridis. ${ }^{22}$ However, given the findings of such reports about the veritable mountains of scrap tires accumulating as global car ownership increases, the present volume of up-cycled tire goods would have to grow many thousands of times over to keep pace. In addition, the fact that recycled tire furniture can be more expensive than original tires (especially when designed and made by developed world businesses, such as Tread) ${ }^{23}$ raises questions about how much value can be added to up-cycled products before the cost of the waste supply is driven up, threatening the primary incentive to up-cycle it.

Accordingly, anyone persuaded to purchase up-cycled goods on environmental grounds may be judged to be making a purchase that is more symbolic of good intentions than it is supportive of

23 Tread, http://mww notonthehighstreet. com/tread [accessed May 11, 2011). 
sustainable design and manufacturing practices. This assumption could present quite a dilemma for Traidcraft. In addition to up-cycled goods, their inventory also includes traditional garments, as well as consumables like cooperatively grown wine, where the ethical endorsement applies to traditional craft production for fair pay in acceptable working conditions. Giving similar endorsement to their range of recycle-reuse products may then create some confusion about whether it is the design of the up-cycled products that is being endorsed, when in fact, the producers appear to have followed rather than led in terms of design and innovation.

\section{Conclusion}

Sustainable design is one small part of an immense global project. The three case studies selected reveal that it is difficult to assess differing sustainable design strategies without acknowledging the great complexity of the global project and the current lack of an overarching set of sustainability metrics that meets the needs of all involved. Natural Step has here been used simply as a first step in trying to assess the sustainability of the three design strategies examined. It has proven useful in exposing some of the difficulties inherent in the Imvubu Projects strategy, but it has also exposed shortcomings in its own method of identifying "natural conditions."

The Legacy Foundation approach seems to be the one that best meets sustainability criteria. Yet its inclusive, devolved approach might come with a price: that the isolated poor might not be as well-equipped as external agencies to design and develop the objects and systems that best meet their own immediate needs. Traidcraft has approached this problem from the other end, where citizens of developing countries involve themselves in free market capitalism and use their profits to increase their capacity to design and make products more sophisticated than they would be if their design-and-make ambitions were restricted to using only the most rudimentary technology and skills. However, because of the enormous capital gap between developing and developed manufacturing nations, the ambitions of the artisanal collectives supported by Traidcraft tend toward the production of "me too" products—ones that lack design originality and an independent brand identity demarcating them from less sustainable competitors. This situation raises some questions about how far up the economic ladder such collectives can climb.

There can be little doubt that the three organizations examined here have developed design strategies that provide invaluable support for needy communities in the developing world. Therefore, any limitations in the sustainability of the design practices noted in these case studies can be viewed positively as ones that offer opportunities for continuing analysis and improvement. 
Copyright of Design Issues is the property of MIT Press and its content may not be copied or emailed to multiple sites or posted to a listserv without the copyright holder's express written permission. However, users may print, download, or email articles for individual use. 